\title{
Vascular Purpura
}

National Cancer Institute

\section{Source}

National Cancer Institute. Vascular Purpura. NCI Thesaurus. Code C35499.

A raised vasculitic hemorrhage into the skin and/or mucous membranes. 